\title{
A construção de significados por meio do projeto gráfico: uma análise dos livros Avenida Niévski e Notas de Petersburgo de 1836, da editora Cosac Naify \\ Book design in meaning-making: a analysis of Cosac Naify's Avenida Niévski and Notas de Petersburgo de 1836
}

\author{
Gabriela Araujo F. Oliveira \& Hans da Nóbrega Waechter
}

design de livros, projeto gráfico, literatura

Por meio da análise de Avenida Niévski e Notas de Petersburgo de 1836, discutimos como o projeto gráfico é capaz de articular significados com o conteúdo textual que configura. Para isso, elaboramos uma ficha de análise composta por (1) ficha técnica, (2) aspectos formais e (3) resenha. A partir da revisão bibliográfica de críticas literárias, aprofundamos a análise do texto e explicitamos a relação dos aspectos formais com o texto literário, argumentando que os dois princípios que regem as escolhas projetuais são (1) a contextualização de espaço e tempo e (2) a simetria. Por fim, argumentamos que o designer deve conceber o projeto gráfico do livro para articular discursos, consciente dos significados que impõe por meio da materialização dos artefatos.

book design, form of the book, literature

By analyzing Avenida Niévski and Notas de Petersburgo de 1836, we discuss how book design contributes to meaning-making of the textual content that it configures. In order to do that, we developed an analysis sheet composed by (1) index sheet, (2) formal aspects and (3) summary. After reviewing literary criticism on the works, we further developed the analysis of the text and point out the relation of the book's formal aspects to the literary text, arguing that the two main principles that conducts design choices are (1) contextualizing space and time and (2) symmetry. Thus, we argue that designers should design books to expand meaning-making possibilities as they create meaning by materializing artifacts.

\section{Introdução}

O designer participa do processo de produção e significação do livro porque articula seus elementos construtivos: aspectos materiais e visuais exercem funções determinantes na experiência de leitura. Diante disso, este artigo explicita a articulação de significados entre elementos do projeto gráfico e conteúdo textual dos livros Avenida Niévski e Notas de Petersburgo de 1836, de Nikolai Gógol, publicados juntos pela Cosac Naify na Coleção Particular. Assim, tratamos design como uma atividade fundamental na construção do livro e de seu significado por meio da materialização do texto, de modo que a análise e a crítica conferem mais possibilidades de interpretação para as obras.

A análise foi informada pela revisão de críticas literárias, a fim de complementar os significados da leitura. Isso foi necessário ao constatarmos que a relevância histórica das obras era um critério determinante para a publicação analisada. Por conseguinte, a fundamentação teórica aprofundou as análises, dando atenção a aspectos já naturalizados dos livros - ou ainda, delinear suas nuances. A sistematização desse processo resultou na elaboração da Ficha de Análise composta de três partes: Ficha Técnica, Aspectos formais e Resenha. Desse modo, a análise articula os significados mais proeminentes do projeto gráfico em diálogo com o texto literário. Com isso, discutiremos como o projeto gráfico pode evidenciar aspectos do texto de maneira que a experiência de leitura seja pluralizada.

Os dois princípios que regem as escolhas projetuais de Avenida... e Notas... são (1) a contextualização de espaço e tempo e (2) a simetria. Para o primeiro aspecto, o invólucro

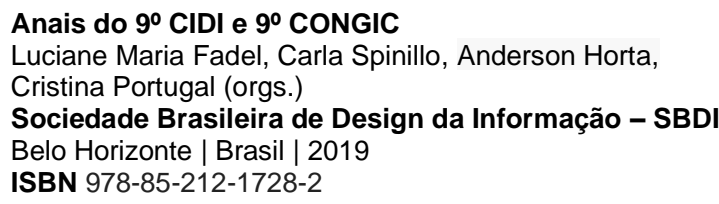

Proceedings of the 9th CIDI and 9th CONGIC Luciane Maria Fadel, Carla Spinillo, Anderson Horta, Cristina Portugal (orgs.)

Sociedade Brasileira de Design da Informação - SBDI Belo Horizonte | Brazil | 2019 ISBN 978-85-212-1728-2 
(sobrecapa), a cor - do volume de Notas... e das gravuras utilizadas - e a escolha da tipografia são os aspectos mais significativos. Para o segundo, o projeto se vale das cores no volume de Avenida..., da separação em dois volumes, da mancha gráfica, da diagramação e da tipografia. Portanto, analisaremos o projeto gráfico enquanto uma série de decisões conscientes que, ao serem justapostas em uma unidade material, constituem uma rede de significados; por isso, a configuração do livro resulta em interpretações complexas e distintas dos textos literários, ao mesmo tempo que também nasce de interpretações.

\section{Ficha de análise}

A análise está pautada na relação entre a interpretação do designer de livros e a realização do projeto gráfico e, portanto, considera a hermenêutica como referencial analítico. Assim, enquanto leitores especialistas, exploramos as possibilidades semânticas dos elementos do projeto gráfico, que perpassa, necessariamente, a interpretação tanto do conteúdo literáriotextual quanto do visual-material do projeto. A ficha de análise estrutura o processo, além de permitir que quem não teve contato com o livro seja capaz de compreender o projeto gráfico e o conteúdo textual, tornando a análise compreensível.

\section{Ficha técnica}

$\mathrm{Na}$ ficha técnica, visamos a catalogar o objeto segundo aspectos técnicos e evidenciar a presença dos atores no processo de realização do livro. A partir do modelo proposto por Lima (2014) adaptamos a catalogação para contemplar mais aspectos relativos à produção gráfica do livro. De maneira iterativa com o corpus analítico e a revisão bibliográfica - sobretudo de dicionários como os de Faria e Pericão (2008) e Porta (1958). Por conseguinte, retiramos e/ou relocamos alguns itens da ficha de Lima (2014) e acrescentamos alguns outros.

\section{Aspectos formais}

Por si só, elencar esses elementos apontam apenas especificidades técnicas gráficas e de produção que talvez não remetam a significados específicos em relação ao texto. Por conseguinte, isso evidencia a importância do designer enquanto ator do processo produtivo, a fim de conferir possibilidades semânticas a essas especificidades. Uma vez que os aspectos formais foram elencados, as análises puderam se aprofundar em como se articulam com os significados do texto. Desse modo, essa parte limita-se a delinear os parâmetros e ferramentas do projeto gráfico, compreendidos enquanto uma abordagem sintática, em oposição à discussão semântica trazida pelas análises. Com isso, os elementos não são tomados isoladamente, mas adquirem sentido quando se articulam com todos os outros os elementos do complexo sistema do livro enquanto objeto.

\section{Resenha}

A resenha conta os eventos da narrativa, evidencia os aspectos mais relevantes para a análise e identifica os elementos literários do texto que dialogam com o projeto gráfico. Por conseguinte, nela não constam referenciais críticos e teóricos pois visa a apresentar os significados resultantes da nossa interpretação. Já que a sinopse é elaborada a partir da leitura da obra e busca evidenciar seus aspectos literários, citamos trechos significativos que demonstram o estilo do texto e do autor. Assim, buscamos explicar a história e trazer a voz do texto para nossa ficha, respeitando suas características literárias, embora necessariamente mais curta e simplificada. Retomamos tais aspectos ao longo da análise através da inclusão das críticas literárias, fundamentando interpretações construídas durante a leitura.

\section{Ficha de análise do objeto}

Nas Figuras 1, 2 e 3 a seguir, é possível verificar a ficha técnica e os aspectos formais da 
Oliveira, G. A. F. \& Waechter, H. N. | A construção de significados por meio do projeto gráfico: uma análise dos livros Avenida Niévski e Notas de Petersburgo de 1836, da editora Cosac Naify

edição que analisaremos. Em seguida, delinearemos os textos por meio das resenhas; nessa seção, todas as citações são de Gógol (2012).

Figura 1: Ficha técnica da edição analisada.

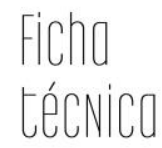

AVENIDA NIÉVSKI E NOTAS DE PETERSBURGO DE 1836
TítULO

Avenida Niévski e Notas de Petersburgo de 1836

AUTOR

Nikolai Gógol

PROJETO GRÁFICO

Elaine Ramos e Gabriela Castro

ILUSTRADOR

ANO

2012

TRADUTOR

Rubens Figueiredo

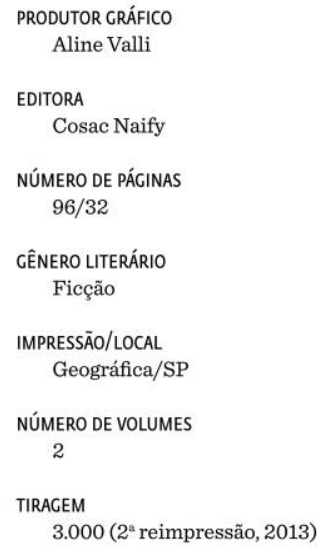

Figura 2: Ficha de aspectos formais do volume Avenida Niévski.

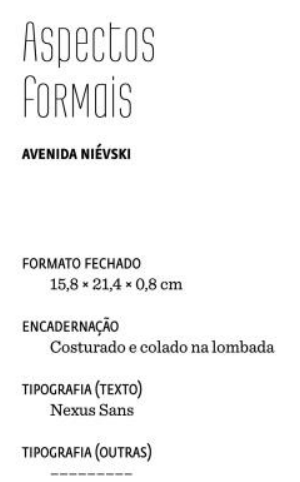

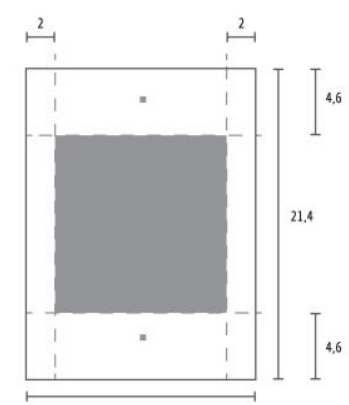

16,2

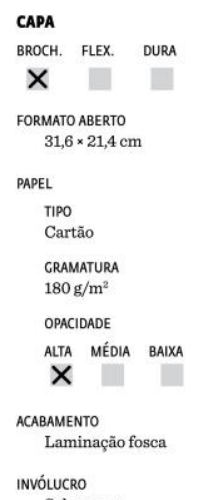

INVóLUCRO
MIOLO

PAPEL

Munken Pure Rough

CRAMATURA
$100 \mathrm{~g} / \mathrm{m}^{2}$

OPACIDADE

ALTA MÉDIA BAIXA

$\times$

ACABAMENTO

Refile trilateral
MANCHA DE TEXTO

CORPO/ENTRELINHA

$11 / 18$

ALNHAMENTO

三

PARÁcrAFO

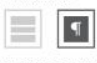

BLOCO DE TEXTO

MARCENS (INT / EXT / SUP / INF)
$2 \times 2,1 \times 4,7 \times 4,6 \mathrm{~cm}$ 
Figura 3: Ficha de aspectos formais do volume Notas de Petersburgo de 1836.
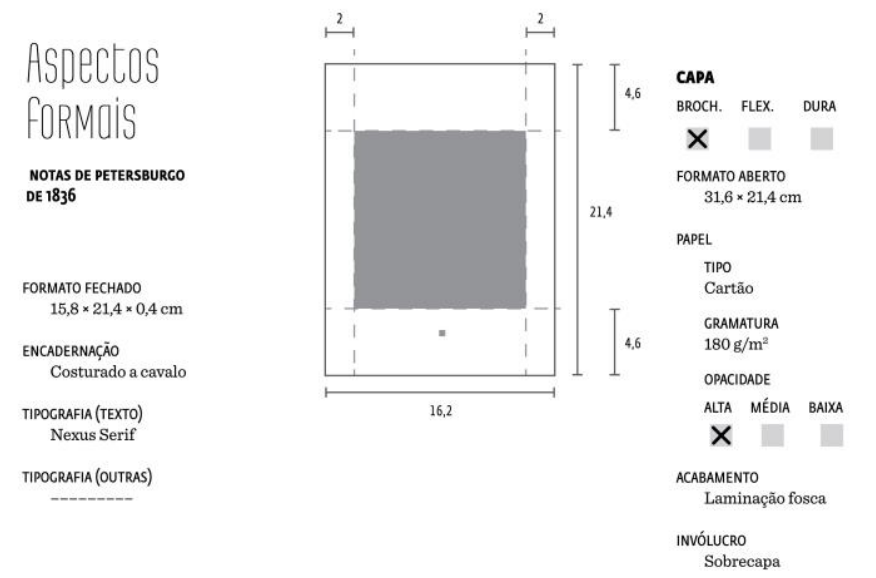
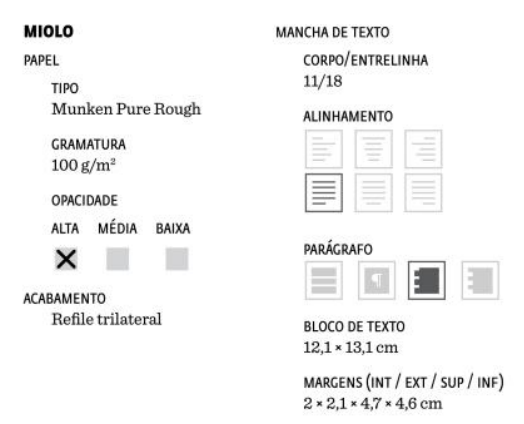

\section{Resenha}

Avenida Niévski e Notas de Petersburgo de 1836 foram textos escritos pelo russo Nikolai Gógol (1800-1852), publicados pela primeira vez em 1835 e 1837, respectivamente. Em Avenida Niévski, o autor retrata o cotidiano da avenida considerada o coração de Petersburgo, então capital do Império Russo.

No início da narrativa, o narrador exalta a avenida, o modo como ela se transforma com o passar das horas e os tipos de pessoas que passam por ela: "Quantas mudanças ela sofre em apenas vinte e quatro horas!" (p.5). Então, ele retrata o encontro de dois rapazes - Piskarióv e Pirogóv - em um rápido diálogo, que se interessam por duas mulheres que estão passando e decidem segui-las. Primeiro, o narrador acompanha a investida do romântico pintor Piskarióv que decide ir atrás de uma mulher de cabelos escuros, misteriosa e vestida elegantemente com uma capa brilhante. Depois de segui-la, Piskarióv fica desiludido ao descobrir que ela morava em um "antro asqueroso onde a lamentável depravação instalava sua morada, fruto da falsa educação e da terrível multidão da capital" (p. 45). Pensando sobre o que vira, Piskarióv cai no sono, mas é acordado por um lacaio que o leva para uma luxuosa casa. Lá, ele avista a moça que seguiu pela avenida Niévski. Então, o narrador fala longamente sobre esse encontro, a conversa, os detalhes do local, a elegância das pessoas. No entanto, esse episódio fora um sonho "Ah, como a realidade é repugnante! O que é ela comparada ao sonho?" (p. 70).

Depois disso, Piskarióv vive à espera do sonho, ou seja, "os sonhos transformaram-se em sua vida (...): Piskarióv, pode-se dizer, dormia acordado e velava dormindo" (p. 73). Com o passar dos dias, ele começa a sentir insônia e, para "salvar sua única riqueza" (p.74), ele toma ópio para recuperar o sono e encontrar a moça novamente. As doses de ópio lhe perturbavam e questionava se adiantava viver dessa forma, em "uma eterna desavença entre o sonho e a existência real" (p. 79). Então, ele cria hipóteses sobre ela, acreditando que vivia ali contra a sua vontade e que desejava se desprender daquela condição. Decide, por fim, pedi-la em casamento, e foi fortemente rejeitado. O pintor, então, volta para a sua casa e tranca-se no quarto, onde é encontrado uma semana depois com a garganta cortada. "Assim morreu, vítima de uma paixão louca, o pobre Piskarióv, discreto, tímido, modesto, infantilmente ingênuo, portador de uma centelha de talento que talvez o tempo pudesse inflamar-se com mais amplitude e brilho." (p. 90).

Então, o narrador volta abruptamente ao tenente Pirogóv - quando ele se separou do pintor e seguiu uma mulher loira - e fala de suas qualidades: "é uma criatura tão admirável que jamais conseguimos calcular de uma só vez todos os seus méritos e, quanto mais o examinamos, mais surgem novas peculiaridades, e uma descrição de todas elas seria interminável." (p. 101). Pirogóv persegue a mulher até chegar ao seu destino e descobrir que ela é casada com um artesão alemão; para encontrá-la na oficina, decide encomendar 
esporas. Quando enfim o tenente vai buscar as esporas, se despede da mulher com um beijo nos lábios em frente ao seu marido e vai embora. Em outro dia, ele a encontra na oficina sozinha, mas só desperta seu interesse quando propõe dançar, mas a beija à força e ela começa a gritar. O marido, então, entra em casa com mais dois amigos e "os três artesãos eram os mais fortes entre todos os alemães de Petersburgo e trataram-no de modo tão brutal e grosseiro que, reconheço, não consigo encontrar palavras para representar esse acontecimento triste." (p. 127). Pirogóv fica indignado e quer falar com o general e contar-lhe a violência dos alemães. A caminho de lá, ele entra em uma confeitaria e passeia um pouco pela avenida Niévski, o que o deixa mais calmo, decidindo não incomodar o general em um domingo. Por fim, esquece o ocorrido.

Por fim, o narrador relata uma avenida completamente diferente daquela do início, apontando-a como traiçoeira, onde nada é confiável, tudo é ilusão. "Ah, não acredite nessa avenida Niévski! Eu sempre me envolvo mais ainda em minha capa quando passo por ela e tento, de todo modo, não olhar para os objetos que encontro" (p. 132).

\section{Notas de Petersburgo de 1836}

No segundo volume presente nesta edição da Cosac Naify, encontramos a primeira tradução em português do artigo Notas de Petersburgo de 1836 escrito por Gógol e publicado originalmente na revista Sovremiénnik, n.6, em 1837. Nele, deparamo-nos com um texto mais jornalístico, criticando a cultura de Petersburgo no século XIX, principalmente o teatro. O texto é divido em duas partes, sendo a primeira destinada a uma comparação entre Moscou e São Petersburgo, e a segunda destinada a uma crítica à cultura de São Petersburgo.

\section{Análise}

Os dois princípios que regem as escolhas projetuais do Avenida Niévski e Notas de Petersburgo de 1836 são a contextualização de espaço e tempo e a simetria. A partir da leitura do conto de Gógol, a ideia de espelhamento fica clara em diversos momentos da narrativa. Além disso, outro aspecto enfatizado no projeto gráfico é o contexto que o autor tentou registrar, através da utilização de elementos que remetem à época e ao espaço referentes à história narrada.

Ambos possuem um caráter "de momento", com o objetivo de registrar a vida cotidiana e tipos sociais da Rússia naquela época - uma influência do Realismo. O Avenida é reconhecido por ser um retrato com marcas impressionistas de um momento modernizante da história russa: depois das primeiras reformas sociais iniciadas pelo czar Alexandre I. Com relação à história da literatura, Gógol, apesar de se encontrar no período romântico, preparou o terreno para o Modernismo. Essa dualidade também remete às personagens do conto e demonstra sua capacidade de escrever textos com aspectos muito diferentes: um conto literário e um texto jornalístico.

Em Avenida Niévski, a simetria é evidente, pois ele inicia e termina o conto com descrições da avenida e seus transeuntes. No entanto, ela é deformada na oposição entre a avenida bela e encantadora que o autor faz nas primeiras páginas e a descrição que ele faz no último parágrafo da história. Outro elemento que evidencia a simetria presente na narrativa de Avenida Niévski é a construção das personagens. Gógol inicia a história do pintor Piskarióv e do tenente Pirogóv em conjunto, mas depois cada um deles vai atrás de uma mulher diferente e Gógol passa a contar suas histórias separadamente, como se um tivesse seguido o caminho oposto ao do outro. 
O primeiro contato que temos com o livro, é a sobrecapa impressa em russo, com um adesivo verde em que constam as informações referentes à publicação (Figura 4). A sobrecapa é uma reprodução de uma lâmina do jornal da época em que se passa a história: o ano 1835 está impresso e visível logo na frente. Ao desdobrá-la (Figura 5A), deparamo-nos com os títulos das duas obras e com o nome do autor, posicionados no meio de suas respectivas capas, alinhados horizontal e verticalmente em relação à página (Figura 5B). Essa dobra não parece acidental, uma vez que mostra essas primeiras informações, anunciando o eixo de simetria horizontal que permeará o projeto de Avenida. Então, percebemos que são dois volumes com títulos, cores e acabamentos diferentes entre si (Figura 5C).

Figura 4: Edição analisada.

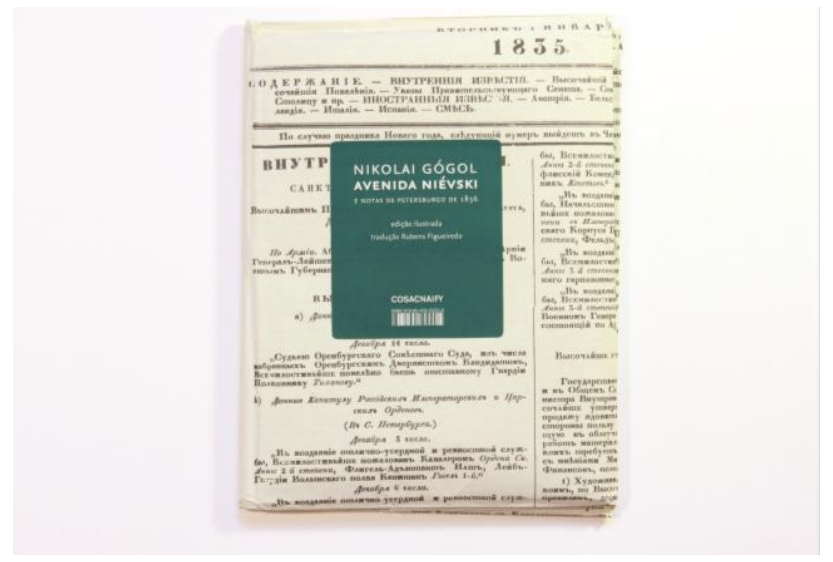

Figura 5: Sequência de imagens mostrando a abertura do invólucro.

A

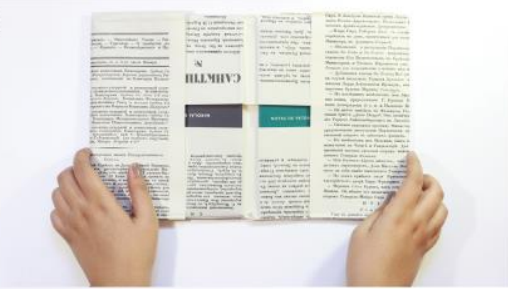

B

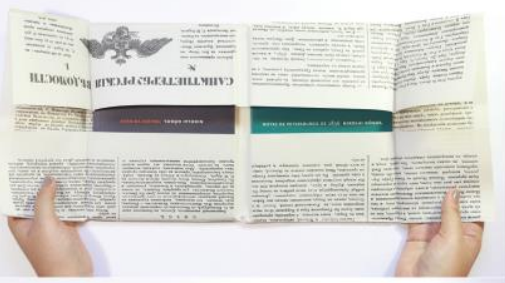

c

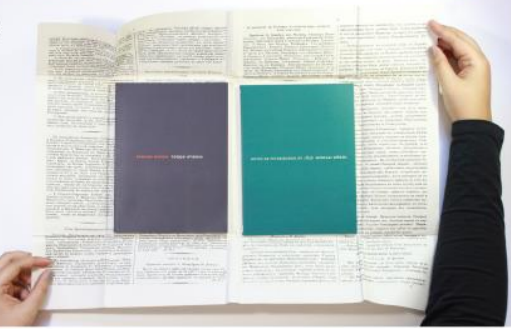

O Avenida tem a sua capa impressa em azul - com o título em laranja e o nome do autor vazado, rotacionado 180 graus - e o Notas está impressa no mesmo verde do adesivo fixado 
na sobrecapa. O posicionamento dos dois títulos e da faixa descoberta pela sobrecapa enquanto a abrimos, já sugere uma horizontalidade que discutiremos adiante. Eles também se diferenciam pela encadernação: Avenida é costurado em cadernos de 16 páginas, colados à lombada, enquanto que Notas é apenas um caderno de 32 páginas com costura aparente. Essa divisão clara entre os volumes é justificada principalmente pelo caráter de cada um dos textos. De um lado, temos um texto literário, e, de outro, um texto de caráter jornalístico, evidenciando a dualidade existente na própria escrita do romântico pré-moderno Nikolai Gógol.

A sobrecapa desdobrada, temos uma página de jornal - sua diagramação e as características da tipografia, apesar do alfabeto cirílico bastante distinto. A presença desse elemento da época na qual a narrativa se passa e, também, contemporânea ao autor, remete o leitor ao tempo e espaço nos quais os textos se originam, uma vez que o jornal continua a exercer uma função simbólica, mesmo depois que a sua função prática deixa de existir. Por isso, não importa que o texto ali seja compreensível para o leitor: sabemos que se trata de um jornal. Ou seja, o que está impresso passa a exercer quase nenhum valor, mas a sua materialidade continua a ser explorada e a ter significado como elemento desse projeto gráfico.

Além disso, o jornal tem um caráter efêmero, dada sua circulação diária (Bogo, 2014). Essa velocidade está presente também na escrita de Gógol, que utiliza um narrador que relata os fatos como em uma conversa, que caracteriza um tipo de narrador não-confiável (Allen, 2013 p. 233). Assim, Gógol narra a morte de Piskarióv de modo sucinto, impedindo que o leitor não tenha reflita sobre a tragédia. Logo, somos levados pela sua ironia no parágrafo seguinte: "Assim morreu, vítima de uma paixão louca, o pobre Piskarióv, discreto, tímido, modesto, infantilmente ingênuo, portador de uma centelha de talento que talvez com o tempo pudesse inflamar-se com mais amplitude e brilho" (Gógol, 2012, p. 90).

\section{Volume I - Avenida Niévski}

O papel cartão da capa tem acabamento laminado fosco, na parte interna, a cor laranja é impressa uniformemente. Essa página abre o caminho para a Avenida Niévski: não há os elementos pré-textuais comuns nos livros literários. Eles dão lugar a uma sucessão de litogravuras retratando a avenida Niévski - feitas por I. Ivánov e P. Ivánov a partir da aquarela de V. Sadonovnikov, publicada entre 1830 e 1835 por André Prévost. As litogravuras estão diagramadas acima e abaixo do eixo horizontal observado na capa. Na parte de cima, temos um panorama do lado esquerdo da avenida Niévski impresso em laranja - o mesmo utilizado no título e na parte interna da capa -, enquanto na parte de baixo temos o panorama do lado direito da avenida impresso em roxo - cor predominante na capa - e rotacionado em 180 graus (Figura 6). Para facilitar a análise, consideraremos a parte acima do eixo central da página como primeiro bloco; e a que está abaixo como segundo bloco, seguindo, dessa forma, o fluxo de leitura da obra (Figura 7).

Figura 6: Primeira página do livro e página dulpa com as imagens do lado esquerdo da Avenida.

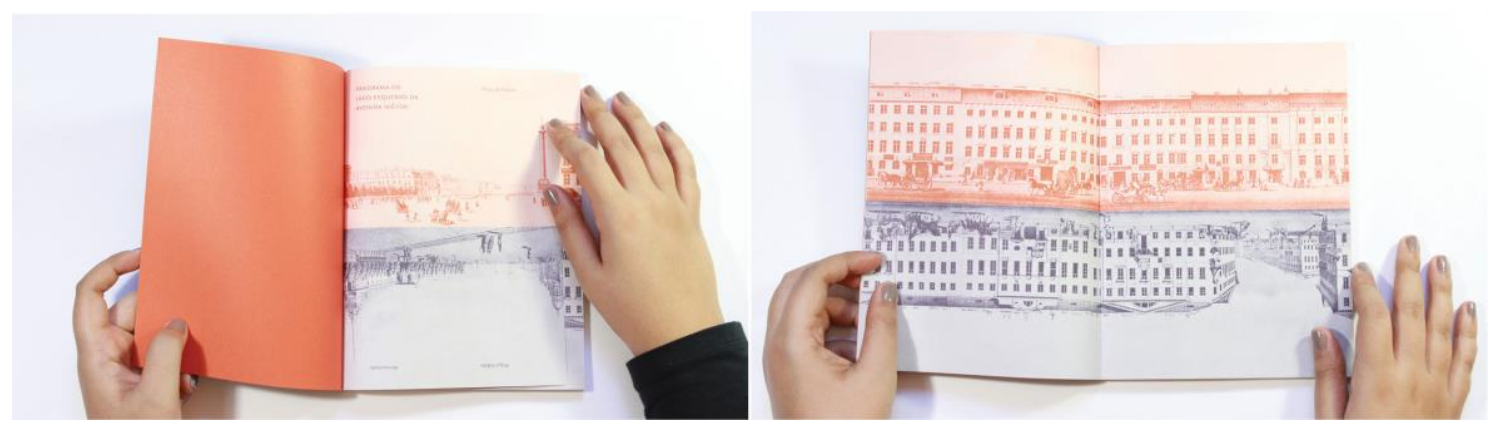


Figura 7: Mancha textual da página dupla.

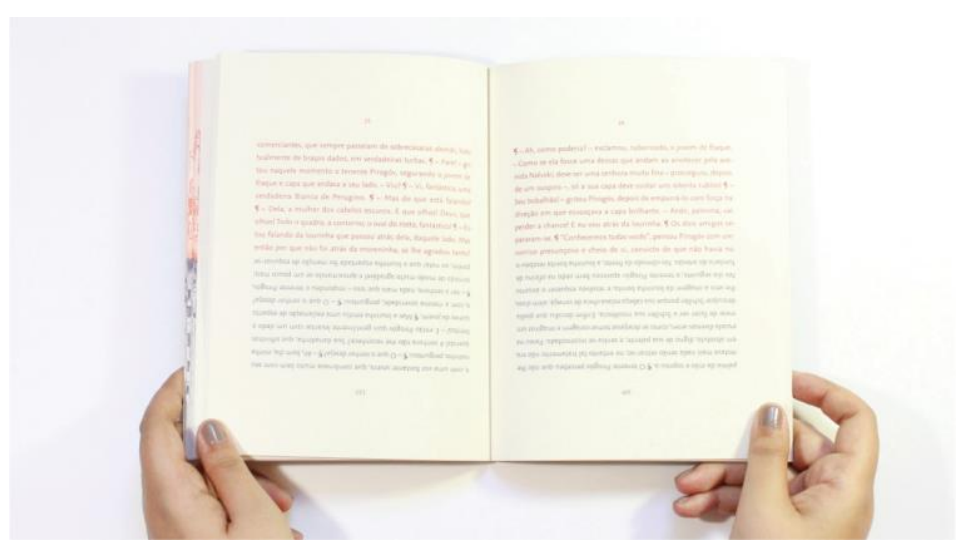

No primeiro bloco, a sequência de páginas com as litogravuras laranja retrata um panorama do lado esquerdo da avenida, também conhecido como o lado brilhante, pois fica ao norte e é onde o sol bate ao longo do dia no verão. Já o lado sul é considerado a "sombra", representada no projeto gráfico pela cor roxa (FIFA, s.d.). No entanto, durante a leitura da obra é comum associar a significação das cores como uma passagem do tempo, uma dicotomia entre o amanhecer e o pôr-do-sol - como apontado por Bogo (2014) - pois Gógol (2012) descreve uma avenida nobre e agradável durante o dia, mas que quando começa a anoitecer se transforma em um antro de ilusões e decepções: "Ela mente o tempo todo, essa avenida Niévski, porém mente sobretudo quando a noite recai sobre ela (...) e quando o demônio em pessoa acende os lampiões, apenas para mostrar tudo sob um aspecto falso" (ibid., p. 134).

A avenida é a personagem principal da trama pois é a partir dela que a história acontece e, segundo o autor, representa tudo para Petersburgo: é um local de encontro, de passagem, de passeio e condensa "linhas diretas e digressivas, escuro e claro, ordem e desordem, sanidade e insanidade [...] condensa contrastes" (Allen, 2013, p.231, t.n.). Por isso, somos apresentados a ela pelas gravuras. Ao passar as páginas, temos a sensação de caminhar nela, observando a arquitetura, as carruagens e os transeuntes. Os principais monumentos ali retratados são acompanhados de uma legenda, quase como em um passeio turístico. Dessa forma, o projeto gráfico procura evidenciar o aspecto histórico pois o texto também registra a vida em São Petersburgo e da Rússia em um momento de intensa modernização. As imagens são diagramadas ocupando a página-dupla, sem margens, fortalecendo a horizontalidade e a sequencialidade do projeto.

Em todo o volume I, a tipografia utilizada foi a Nexus Sans (Figura 8), desenhada entre 2002 e 2004 pelo holandês Martin Majoor e publicada pela fundição tipográfica alemã FontFont em 2004. Ao desenhar a Nexus, o tipógrafo criou uma nova filosofia para o seu design de tipos: enquanto o princípio que guiou a construção da Scala e da Seria - tipografias desenhadas por Martin Majoor - foi "duas tipografias, um princípio formal", com a Nexus ele modificou essa teoria para "três tipografias, um princípio formal" (Majoor, 2007). O princípio utilizado no desenvolvimento dessa tipografia foi o de conexão, que é o significado de nexus em latim (Majoor, 2010). Ele desenhou três tipografia conectadas entre si: serifada, sem serifa e slab, denominadas Nexus Serif, Nexus Sans e Nexus Mix, respectivamente. A Nexus Mix foi nomeada dessa forma por ser resultado de uma mistura do desenho da serifada com a sem serifa. 
Oliveira, G. A. F. \& Waechter, H. N. | A construção de significados por meio do projeto gráfico: uma análise dos livros Avenida Niévski e Notas de Petersburgo de 1836, da editora Cosac Naify

Figura 8: Tipografia principal utilizada no projeto gráfico do livro Avenida Niévski.

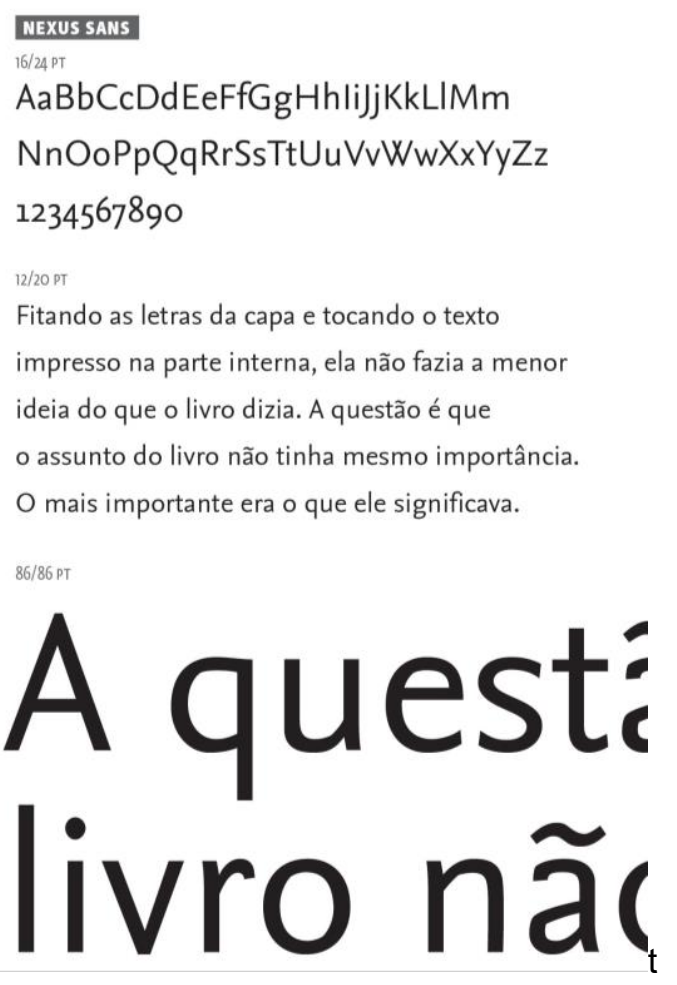

O princípio de conexão utilizado para desenvolver a tipografia também está presente na estrutura do projeto gráfico. Avenida e Notas são textos originalmente publicados separadamente e possuem naturezas diferentes. No entanto, existe uma conexão evidente entre eles: São Petersburgo, o local que protagoniza ambos. E, apesar de serem textos independentes, um ajuda a compreender melhor o outro devido à dualidade das características da escrita de cada um deles.

Para esse projeto, seria possível escolher várias tipografias desenvolvidas no século no qual a história se passa, como a Clarendon, Century ou Akzidenz Grotesk. No entanto, foi escolhida uma tipografia contemporânea, mas com caráter humanista - com características do Renascimento. Essa escolha pode ser compreendida como um recurso para trazer a história para a atualidade, porque mesmo sendo escrita no século XIX, os temas tratados por Gógol ainda são pertinentes para a nossa sociedade.

Além disso, a escolha de uma tipografia de uma fundição tipográfica alemã não foi por acaso. Tanto em Avenida quanto em Notas, Gógol (2012) evidencia bastante a presença dos alemães em Petersburgo, principalmente quando compara a Alemanha com Moscou: "Moscou até agora é uma barba russa, e Petersburgo já é um alemão perfeito" (Gógol, 2012, p. 4) e "Petersburgo é um sujeito caprichoso, absolutamente alemão, tudo observa e calcula (...); Moscou é um nobre russo e, se já está alegre, então se alegra de uma vez até cair,(...); Moscou não ama o meio-termo" (ibid., p. 5).

Enquanto algumas decisões projetuais demonstram a tentativa do texto de registrar um espaço e tempo específicos, outros demonstram um segundo conceito fundamental: a simetria. Há uma dualidade que perpassa a construção do conto: nas personagens, em sua estrutura e no motivo de sonho e realidade. Assim, encontramos no projeto aspectos que reforçam sua dualidade: nas cores, nos dois volumes, na mancha gráfica, nas imagens e na tipografia, como analisaremos a seguir.

A mancha textual é simétrica e quadrada, remetendo diretamente à escrita de Gógol, que 
tanto começa quanto termina a narrativa falando sobre a avenida, mas de maneiras diametralmente opostas. No início, exalta a Avenida Niévski: "Não há nada melhor do que a avenida Niévski, pelo menos em Petersburgo; para a cidade, ela representa tudo." (Gógol, 2012, p.1). Por outro lado, no final, descreve uma avenida completamente diferente: "Tudo é ilusão, tudo é sonho, nada é o que parece!" (ibid., p. 132). O alinhamento do texto justificado e hifenizado - com ajustes ópticos para alinhar a pontuação no fim da linha - espaceja as palavras de maneira consistente, de modo que fortalece a simetria da mancha. Além disso, não há recuo nem distância entre os parágrafos. Nesse projeto, foram utilizadas marcas de parágrafo (ou pé-de-mosca), fortalecendo a simetria da mancha textual (Figura 96).

Além disso, a mancha textual ocupa um espaço semelhante ao que as construções arquitetônicas ocupam nas litogravuras, caracterizando uma grande margem superior na página. Já que o tamanho da caixa de texto determina a velocidade que o leitor passará as páginas, seus pequenos blocos de texto, faz com que o leitor avance as páginas com rapidez, facilitada também pelo texto ter uma caráter de relato e uma linguagem cotidiana. Dessa forma, o leitor tem a sensação do ir (primeiro bloco) e vir (segundo bloco) refletidos no passar das páginas (Bogo, 2014).

O formato de $15,8 \times 21 \mathrm{~cm}$ é propício para uma leitura confortável, pois não é necessário ler o livro em cima de uma mesa ou de um suporte. Por ser uma capa brochura, a abertura do livro é mais flexível, além de deixa-lo mais leve se comparado a um livro de capa dura. Além disso, essas características fazem com que o ato de virar o livro, para ler as informações que estão de cabeça para baixo, não seja incômodo.

\section{Volume II - Notas de Petersburgo de 1836}

O segundo volume contém o artigo Notas de Petersburgo de 1836 (Figura 9), publicado originalmente em 1837, na revista Sovremiénnik (“O Contemporâneo"), n. 6. Nele, percebemos um Gógol menos irônico, de tom jornalístico, avaliando a vida cultural da então capital da Rússia no século XIX. Na primeira parte, há uma comparação entre Moscou e Petersburgo, confrontando as características das duas cidades. Enquanto que, na segunda parte, faz uma crítica à cultura de São Petersburgo, discursando sobre a produção dos balés em Paris, Petersburgo e Berlim, o interesse dos habitantes de Petersburgo em teatro, a Quaresma na cidade e o que resta de Petersburgo depois da páscoa, situando o leitor na cultura da época.

Figura 9: Capa do livro Notas de Petersburgo de 1836.

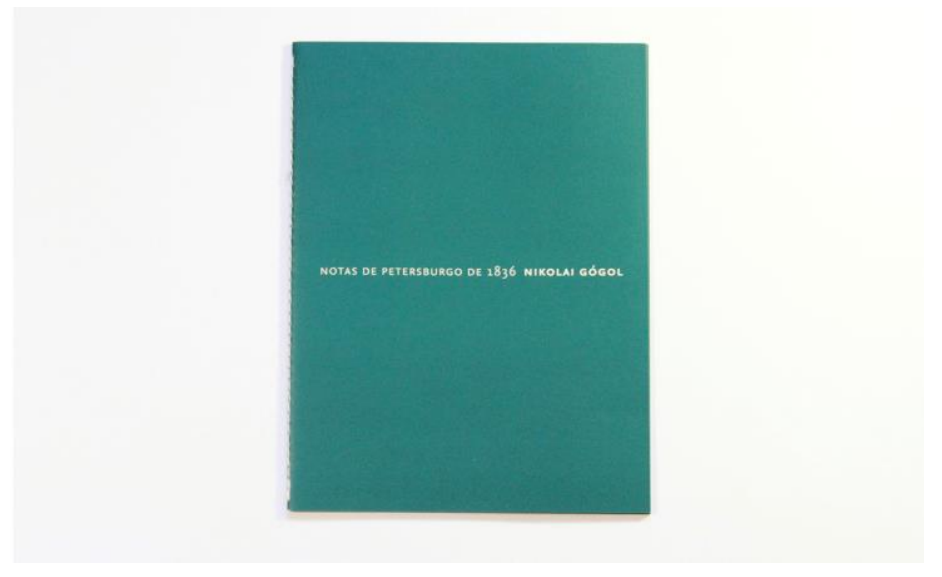

A cor verde é utilizada em todo o segundo volume (capa e miolo) com a tipografia vazada em branco (Figura 10). Na busca da relação entre a cor verde e Petersburgo, verificamos que essa edição contou com uma pesquisa iconográfica, feita pela jornalista Marina Darmaros, brasileira residente em Moscou desde 2007 que possui artigos e matérias em diversos portais de notícias - Folha de S. Paulo, G1, Observatório da Imprensa, Gazeta Russa - em que trata 
Oliveira, G. A. F. \& Waechter, H. N. | A construção de significados por meio do projeto gráfico: uma análise dos livros Avenida Niévski e Notas de Petersburgo de 1836, da editora Cosac Naify

da vida na Rússia. Por conseguinte, há evidências para acreditar que o projeto gráfico traz características muito cotidianas da cultura russa. Assim, em pesquisa visual da arquitetura de São Petersburgo, encontramos vários monumentos pré-soviéticos que têm o verde como cor predominante, tais como o Teatro Mariinsky, a Green Bridge, o Palácio de Inverno e alguns detalhes da arquitetura, como a abóbada da Catedral de Kazan. Isso parece indicar que o verde tem relação com uma memória cultural de São Petersburgo, sendo utilizada no projeto gráfico como mais um elemento para remeter à cidade e ao tempo que Gógol tenta registrar.

Figura 10: Páginas internas do volume II.

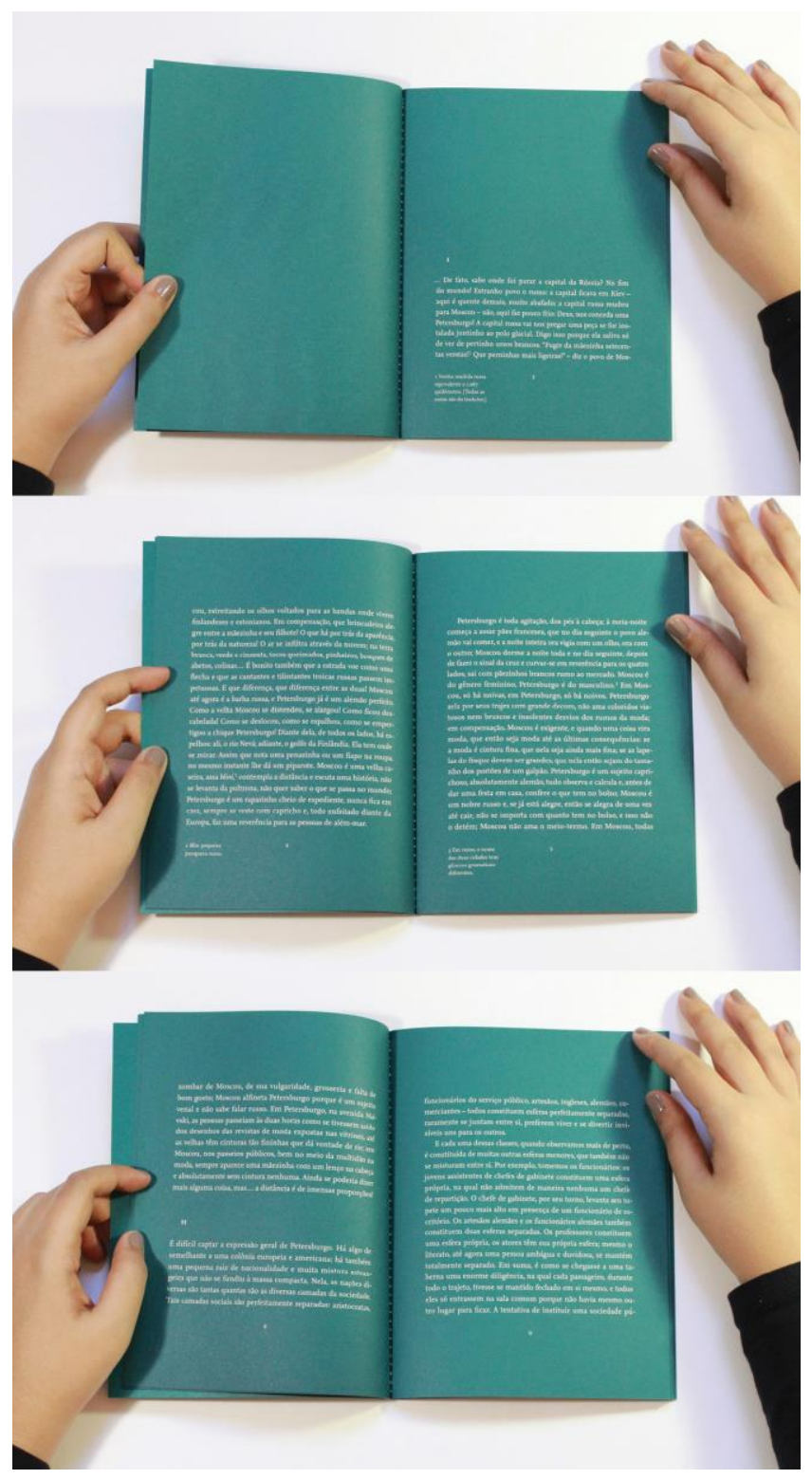

Por outro lado, outras decisões retomam a dualidade e simetria presentes no projeto gráfico e no texto de Gógol. Enquanto no Avenida Niévski o texto é colorido sobre a folha branca, em Notas de Petersburgo de 1836, o texto é vazado sobre o verde impresso no papel. Dessa forma, podemos compreender o uso das cores nos dois volumes a fim de enfatizar o tempo e o espaço de São Petersburgo da época. No entanto, essa simetria também é deformada: enquanto, em um volume, a cor representa o tempo e o espaço de maneira cotidiana - pela

Anais do 9 Congresso Internacional de Design da Informação | CIDI 2019 
luminosidade do dia e pelo lado avenida -, no outro o faz de uma perspectiva mais distante - 0 entorno mais amplo e um período histórico - embora a avenida seja sempre protagonista.

\section{Considerações finais}

Consideramos que o texto não existe quando não é feito transmissível (Cf. Chartier, 1995) - em particular, feito visível através da linguagem visual - e, no caso dos livros, o projeto gráfico é tido como decisões conscientes que, ao serem justapostas em uma unidade material, constituem uma rede de significados. Nesse sentido, a atuação do designer de livros contemporâneo tem se voltado para a criação de redes de significados materializados em um objeto, distanciando a prática do paradigma da funcionalidade do design moderno. Por conseguinte, suscita-se o que se tem chamado de "renascimento dos livros" (Cf. Souza et al, 2018).

A partir de revisão de críticas literárias, pudemos compreender a importância do autor e dos textos da edição, fazendo com que as escolhas projetuais passassem a reforçar ou alterar os significados da publicação. No caso de Avenida Niévski e Notas de São Petersburgo de 1836, de Nikolai Gógol, constatamos que os dois princípios que norteiam o projeto gráfico são (1) a contextualização de espaço e tempo e (2) a simetria, que estão intimamente relacionados com o conteúdo textual e com a caracterização do autor na história da literatura.

A ficha de análise nos permitiu aprofundar na leitura a fim de articular os significados do texto com os do projeto gráfico. Ela pode ser um ponto de partida para as próximas pesquisas que visam a fazer do projeto gráfico uma linguagem para a construção do livro. A sua divisão em três partes tem como objetivo fazer com que o leitor veja o que ele apenas reconhece: a forma do livro como um aspecto fundamental da experiência de leitura.

Dessa perspectiva, buscamos encorajar que o designer se valha de suas ferramentas nesse caso, do projeto gráfico do livro - para articular discursos, incentivando uma prática mais autônoma e consciente dos significados que impõe por meio da materialização dos artefatos. Em última instância, isso significa reconhecer sua importância social, tanto em termos de processo produtivo quanto de funções simbólicas.

\section{Referências}

Allen, S.L. (2013) EccentriCities: Writing in the margins of Modernism: St. Petersburg to Rio de Janeiro. Oxford: Oxford University Press.

Bogo, M.B. (2014). A coleção particular da Cosac Naify: explorações sensíveis do gosto do livro. 30 jun, 20. 226p. Dissertação - Universidade de São Paulo.

Chartier, R. (1995). Forms and meanings: Texts, Performances and Audiences from Codex to Computer. Philadelphia: University of Pennsylvania Press.

Faria, M.I. \& PERICÃO, M.G. (2008). Dicionário do livro: da escrita ao livro eletrônico. São Paulo: Editora da Universidade de São Paulo.

Fifa, 2018 World Cup Organising Committee. Nevsky Prospekt. Rússia, s.d. Disponível em: <http://welcome2018.com/en/routes/saint-petersburg/nevsky-prospekt/>. Acesso em 13 mai. 2016.

Gógol, N. (2012). Avenida Niévski. Tradução Rubens Figueiredo. São Paulo: Cosac Naify.

Lima, G.C. (2014). O Gráfico Amador: As origens da moderna tipografia brasileira. 2 ed. Rio de Janeiro: Verso Brasil.

Majoor, M. (2007) FF Nexus: A three-way conversation in type. FontFont Focus. São Francisco: FSI FontShop International. Disponível em: 
Oliveira, G. A. F. \& Waechter, H. N. | A construção de significados por meio do projeto gráfico: uma análise dos livros Avenida Niévski e Notas de Petersburgo de 1836, da editora Cosac Naify

<http://www.martinmajoor.com/4.1_nexus_article_majoor.html>. Acesso em 10 mai. 2016.

(2010) My type design philosophy. [S.I.], 2010. Disponível em:

<http://www.martinmajoor.com/6_my_philosophy.html>. Acesso em 10 mai. 2016.

Porta, F. (1958). Dicionário de artes gráficas. Rio de Janeiro: Editora Globo.

Sobre o(a/s) autor(a/es)

Gabriela Araujo F. Oliveira, Doutoranda, UFPE, Brasil<gabrielaa.araujo@gmail.com>

Hans da Nóbrega Waechter, PhD, UFPE, Brasil <hnwaechter@gmail.com> 